\title{
Analysis on the Low Speed Performance of an Inward-Turning Multiduct Inlet for Turbine-Based Combined Cycle Engines
}

\author{
Chengxiang Zhu $\mathbb{D}^{D}$, Haifeng Zhang $\mathbb{D}$, Zhancang Hu $\mathbb{D}$, and Yancheng You $\mathbb{1}$ \\ School of Aerospace Engineering, Xiamen University, Xiamen 361005, China \\ Correspondence should be addressed to Chengxiang Zhu; chengxiang.zhu@xmu.edu.cn \\ and Yancheng You; yancheng.you@xmu.edu.cn
}

Received 11 March 2019; Revised 5 September 2019; Accepted 21 October 2019; Published 7 December 2019

Academic Editor: Andre Cavalieri

Copyright (c) 2019 Chengxiang Zhu et al. This is an open access article distributed under the Creative Commons Attribution License, which permits unrestricted use, distribution, and reproduction in any medium, provided the original work is properly cited.

\begin{abstract}
The multiduct inlet for turbine-based combined cycle engines receives a lot of attention on its aerodynamic performance. Aside of the most studied mode of transition processes, another significant severe issue regarding the aerodynamic performance of the turbine duct (T-duct) at ground states has rarely been investigated which indeed directly determines the operability and reality of similar engine systems; this issue will be addressed in the present work. Our numerical and experimental studies of an inward-turning tetraduct inlet indicate that the performance of the T-duct is seldom affected by the angle of attack, which however is of crucial importance for takeoff/landing of flight vehicles. The two T-ducts exhibit weak asymmetrical aerodynamic performance during experiment due to nonsynchronization as well as mechanical oscillation of the two turbine engines. With increasing inflow speed, the surface pressure and the total pressure recovery increase accordingly. At $\mathrm{Ma}_{\infty}=0.24$, the total pressure recovery achieves 0.96 at the exit of the turbine duct which is acceptable for the engine to generate sufficient thrust for horizontal takeoff. A further quantitative comparison between simulation and experiment reveals a maximum deviation of only $3 \%$ in terms of both surface pressure and total pressure recovery.
\end{abstract}

\section{Introduction}

Hypersonic travelling has attracted intensive attention from both scientific and commercial communities recently. The difficulty however lies in the propulsion system which must satisfy the requirement of horizontal takeoff/landing and generate sufficient thrust at subsonic, transonic, supersonic, and even hypersonic speeds. The requirement of a wide working range promises that the only solution is an efficient combination among turbine, rocket, ramjet, or scramjet engines. Various concepts of a combined cycle engine have been proposed by different organizations historically. For example, the Long-Term Advanced Propulsion Concepts and Technologies (LAPCAT) in Europe is aimed at developing a hypersonic transport aircraft with Reaction Engines Ltd. The Scimitar engine is based on the combined concept of a precooling turbine engine and ramjet technology $[1,2]$. The Japan Aerospace Exploration Agency (JAXA) has started the research of a hypersonic combined cycle engine since the 1990s and claims to develop a demonstration prototype of the S-engine before 2025, which will be installed on a Mach 5 hypersonic transport airplane [3]. In the USA, the Air Force Research Laboratory (AFRL) and National Aeronautics and Space Administration (NASA) are continuously supporting a combined cycle engine project for the purpose of developing a "Trijet" engine which has a triple suite of propulsion engines (turbine, ejector-ramjet, and dual-mode ramjet) [4, 5]. The Beijing Power Machinery Research Institute is creating a turbo-aided rocket-augmented ramjet combined cycle engine (TRRE), which consists of a turbine path and a rocket/ramjet path with a two-dimensional dual-duct over/under variable inlet $[6,7]$. However, the TRRE inlet shoulder, the compression ramp, and the splitter are all variable in order to meet the requirement of a wide working range, which makes the mechanical control and operation feasibility big challenges. Regarding the aerodynamic performance, twodimensional inlets also encounter many disadvantages compared to three-dimensional inward-turning inlets, e.g., high 


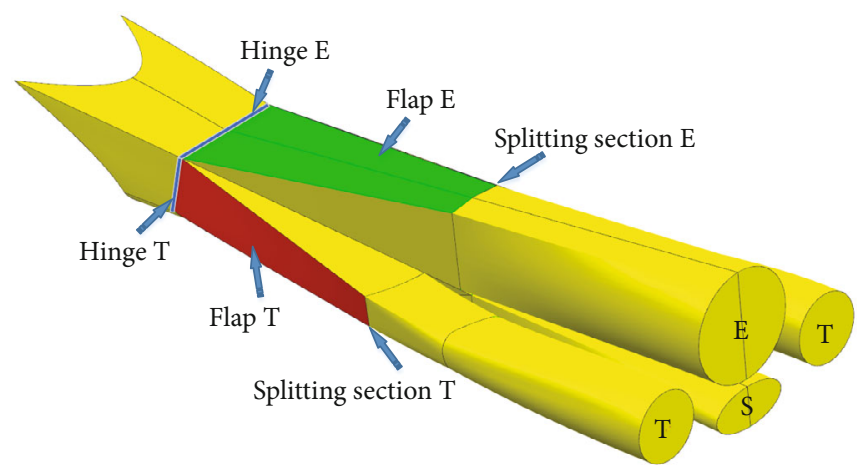

FIGURE 1: Configuration of the three-dimensional inward-turning tetraduct inlet, where $\mathrm{E}, \mathrm{T}$, and $\mathrm{S}$ denote the flow path for ejector-ramjet engine, turbine engine, and scramjet engine, respectively.

drag force, complex corner flow, and low mass flow rate at off-design points [8]. Therefore, a three-dimensional inward-turning tetraduct inlet is designed with only simple rotational flaps to meet the demand of combined cycle engines consisting of turbine, ejector, ramjet, and scramjet engines. Referring to the literatures, most research efforts of the multiduct inlet have been put on the mode transition processes [9-11], but with lack of recognition of the performance during low speed horizontal takeoff/landing. The aerodynamic performance of the combined inlet at ground states directly determines the operability and reality of similar engines, which however attracts minor attention. Therefore, systematic studies focusing on the aerodynamic characteristics of the T-duct at takeoff/landing speeds have been performed both numerically and experimentally in the present work. The content is constructed as follows: first is the description of the adopted numerical and experimental setups. Following that, the aerodynamic performance of the multiduct inlet under various conditions is analyzed from both numerical and experimental aspects, where the influences of inflow speed, attack angle, and rotational speed of the turbine engines are addressed. Thereafter, a quantitative comparison between simulation and experimental results is provided to discuss about the consistency. The last is the conclusion.

\section{Numerical and Experimental Setups}

2.1. Combined Inlet Model. A three-dimensional inwardturning tetraduct inlet for turbine-based combined cycle engines has been designed in the present paper based on the methodology proposed in Ref. [12]. But different from the previous upper arrangement of a single duct for the turbine engine (referred to as T-duct hereafter) in Ref. [12], two T-ducts are adopted in this work in order to meet the mass requirement of the combined cycle engine. The configuration of the tetraduct inlet is shown in Figure 1, where the two side ducts denoted by $\mathrm{T}$ are the flow paths for the turbine engine, the upper duct corresponds to the flow path for the ejector-ramjet engine (referred to as E-duct hereafter), and the lower duct is the flow path for the scramjet engine (referred to as S-duct hereafter). The S-duct is designed based on the ICFD flowfield firstly according to the mass require- ment of the scramjet engine under cruise conditions [1315]. A quasirectangular intake shape is selected for the inlet showing the advantages of easier implementation of rotational flaps around hinges (i.e., flap $\mathrm{E}$ rotates around hinge $\mathrm{E}$, flap $\mathrm{T}$ rotates around hinge $\mathrm{T}$ ) on the compression surface and convenience for mechanical production. The E-duct is located on the top side as an individual flow tube which changes the cross-section shape from rectangular at the splitting section to circular at the exit plane. The cross-sections of the two T-ducts also vary from rectangular to circular shapes with a weak expansion ratio of 1.25 . The control equation of the center line of the T-duct is governed by a fourth-order polynomial equation given by Davic $[16,17]$.

2.2. Numerical Setups. Numerical simulations are conducted based on the commercial software Ansys Fluent 14.0@. Density-based steady Reynolds-Averaged Navier-Stokes (RANS) equations are solved, where the two-equation $k-\omega$ Shear Stress Transport (SST) turbulence model is adopted. The flux term is solved with the Roe-FDS (Roe fluxdifference splitting) scheme. The $1^{\text {st }}$-order upwind scheme is used to discretize the equations spatially to get a stable initial flowfield, based on which the $2^{\text {nd }}$-order upwind scheme is further applied for a refined resolution. The fluid is treated as an ideal gas, and the Sutherland equation is adopted for the computation of viscosity. For all simulations in the present work, the courant number is chosen as 1 . Numerical convergence is adequately evaluated by a residual decrease of at least three orders of magnitude as well as a stable mass flow rate.

Only half of the inlet is simulated considering its symmetric configuration. A large computational domain is used in order to promise sufficient simulation accuracy at low subsonic speed inflow conditions, as shown in Figure 2(a), where the dimensions are normalized to the exit diameter $D=68$ $\mathrm{mm}$ of the T-duct. The boundaries of the large computational domain are set as the pressure-far-field condition except for the right surface which is set as the pressureoutlet condition. The surface of the inlet is set as the no-slip wall, and the exit planes of different ducts are set as pressure-outlet conditions. Figure 2(b) shows the grid structure at the exit plane of the three ducts used for our simulations. Three different grid resolutions (i.e., 3.5, 7.5, and 10 million) are adopted to validate the mesh dependency. The 


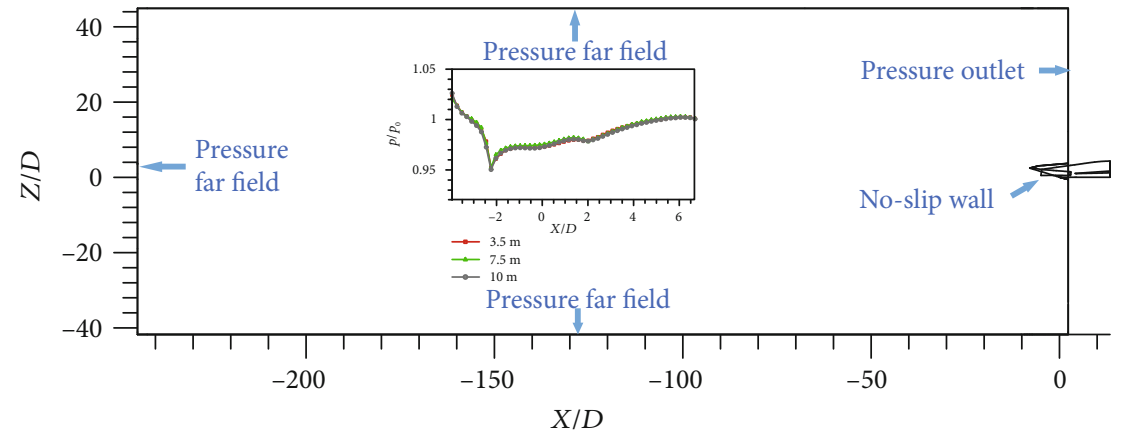

(a)

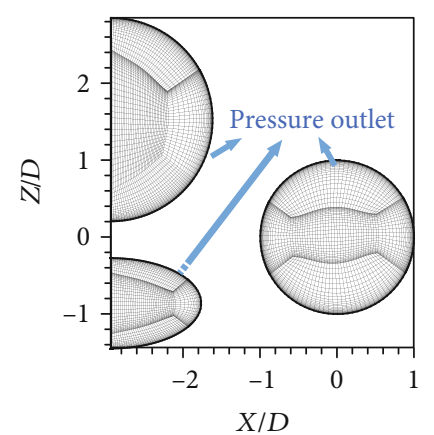

(b)

Figure 2: (a) Computational domain for numerical simulations. The inset shows the validation of the grid dependency. (b) Structured grid at the exit plane of the inlet.

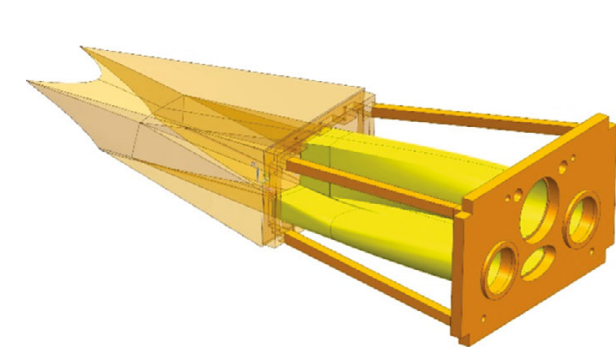

(a)

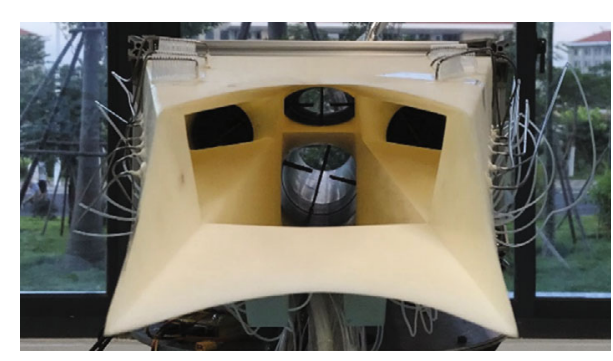

(b)

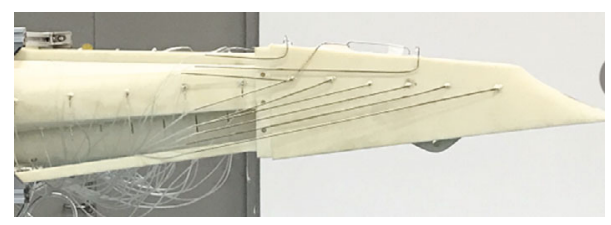

(c)

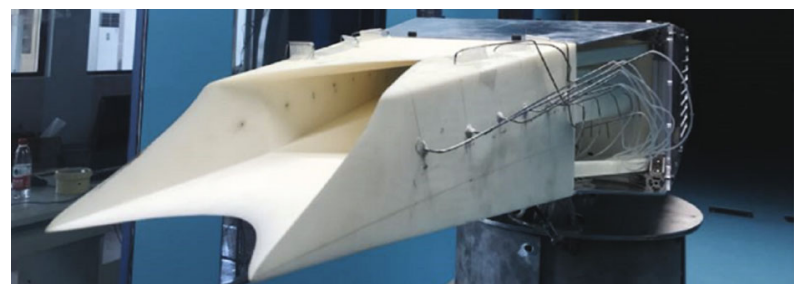

(d)

FIGURE 3: Experimental model of the multiduct inlet. (a) Inlet model to be processed for manufacturing. (b) 3D printed inlet. (c) Arrangement of transducers for pressure measurements. (d) Installation status of the inlet inside the wind tunnel.

pressure distributions along the wall with different grid resolutions are shown as the inset of Figure 2(a), where only limited deviation can be observed. Therefore, the moderate 7.5 million grid is finally selected for all numerical simulations in the present work.

2.3. Experimental Setups. The experimental model of the combined inlet is provided in Figure 3, where Figure 3(a) is the inlet model to be processed for manufacturing. In order to ensure the strength of the inlet and the accuracy of experimental results, the inlet is thickened into a near-rectangular outer shape, which is further linked to the downstream connecting plate by four linear ribs. Figure 3(b) is the 3D-printed inlet model, where the upper duct is the S-duct, the lower duct is the E-duct, and the two side ducts are T-ducts. During the wind tunnel test experiments, the two turbine engines are operated with different rotational speeds, resulting in various backpressures for the inlet. Figure 3(c) illustrates the position of the transducers arranged on the side wall of the T-duct.
Each T-duct has 11 transducers on the side wall and 12 transducers on the top and the bottom wall to measure the static pressure, along with 9 sensors at the exit of each duct which can be rotated to measure the total pressure. Figure $3(\mathrm{~d})$ gives the installation status of the inlet model inside the wind tunnel.

Experiments were performed in the low speed close-type wind tunnel at Xiamen University of Technology, where the maximum inflow speed can be Mach number 0.3 and the size of the test section is $2.6 \mathrm{~m} \times 2.8 \mathrm{~m}$. The experimental setup of the wind tunnel test is sketched in Figure 4, where all the supplementary systems, e.g., the DY-IS electronic control unit, DM542 motor controller and driver, and 9116PSI pressure data acquisition system, are located outside the test section. The two gas turbine engines with rotational speed varying between 0 and $117000 \mathrm{rpm}$ are assembled at the exit plane of the inlet. Static and stagnation pressures are measured by the 9116 PSI with accuracy of $\pm 0.05 \%$ and frequency of $500 \mathrm{~Hz}$. The rotational speed of the gas turbine engines as 


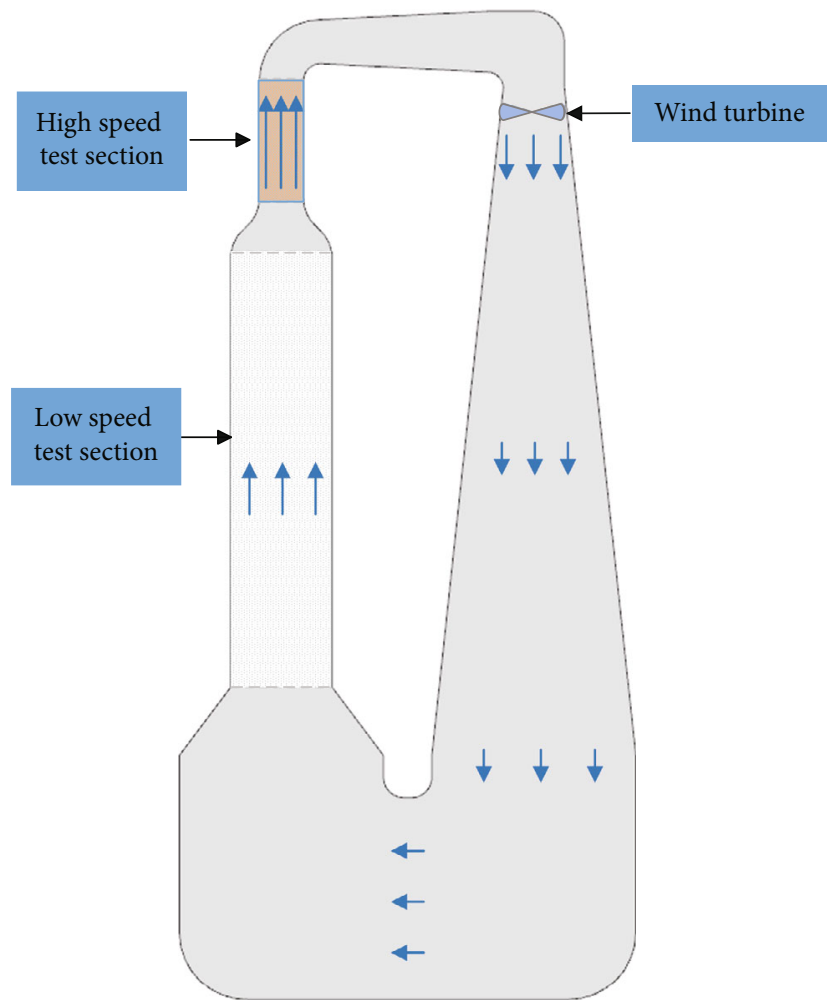

(a)

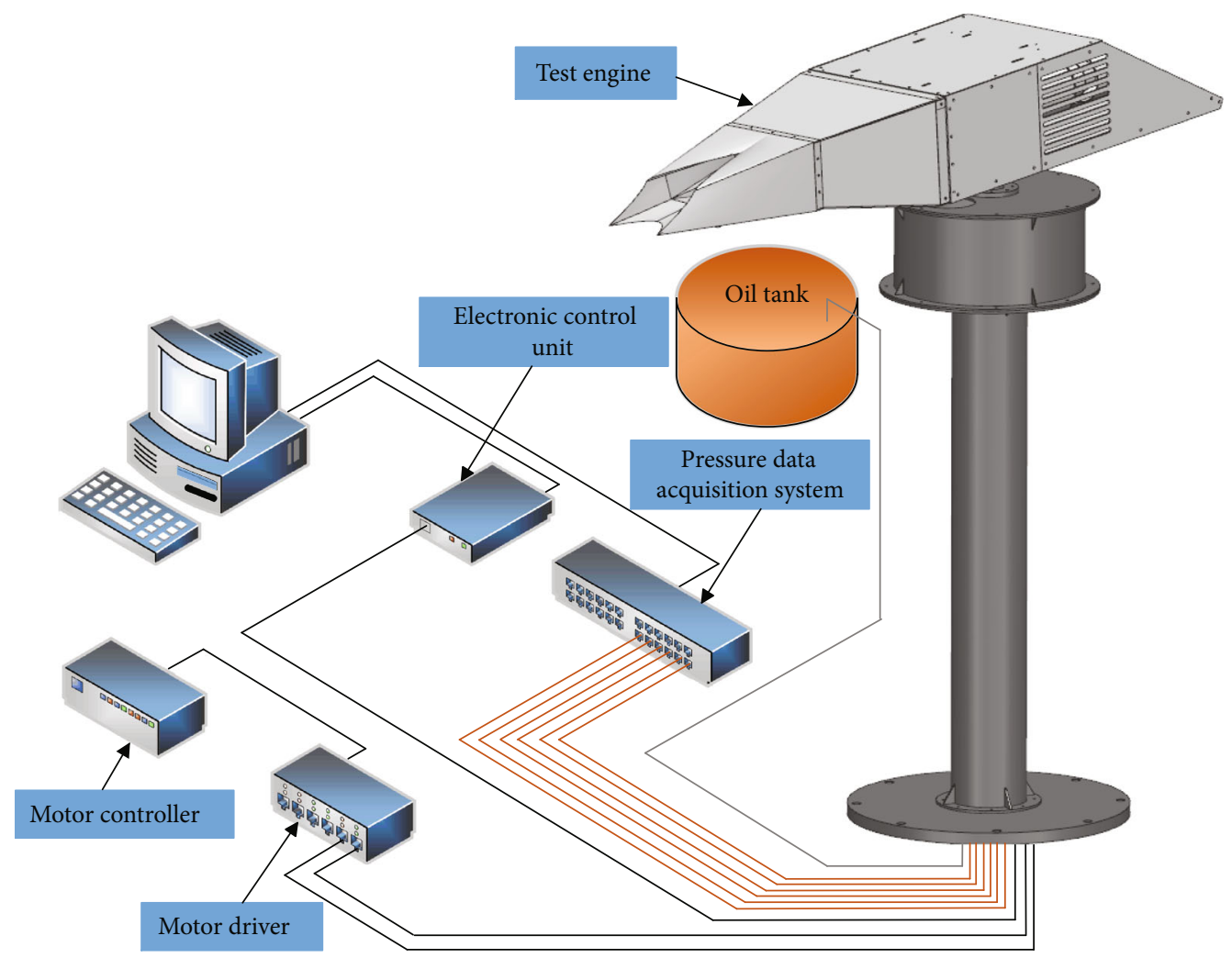

(b)

Figure 4: (a) General configuration of the wind tunnel. (b) Schematic illustration of the experimental setups. The model is assembled inside the test section in the wind tunnel, while all the supplementary systems are located outside. 


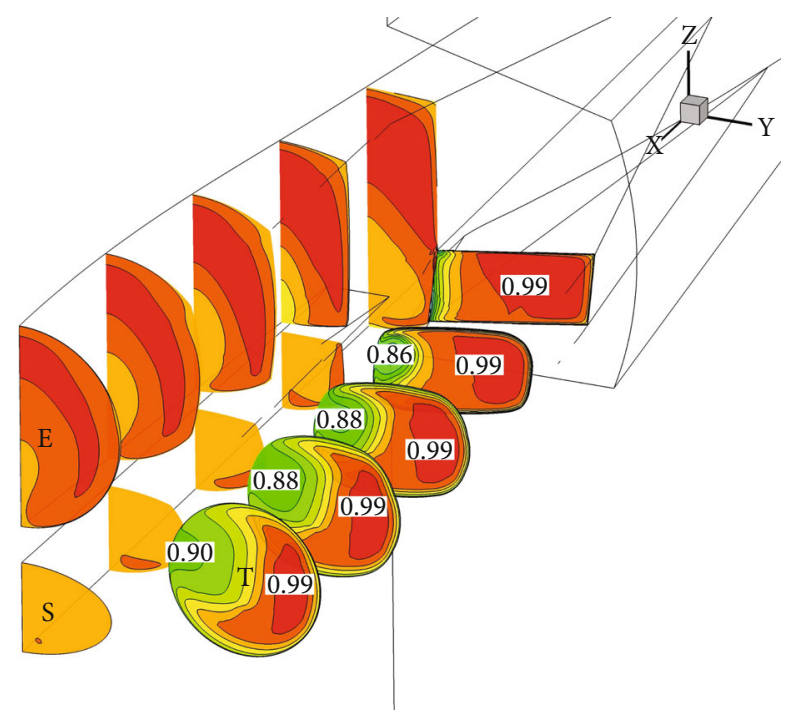

FIGURE 5: Slice views of the total pressure recovery distributions inside the multiduct inlet at $\mathrm{Ma}_{\infty}=0.24$.

well as their fuel consumption can be directly obtained from the engine control unit. The engine thrust is measured by a balance installed between the engine and the basement with accuracy of $0.2 \%$. In order to get accurate averaged pressure and thrust data, the measuring time of each state lasts for 30 s. For more experimental details, please refer to Ref. [18].

\section{Results and Discussion}

3.1. Numerical Results. The three-dimensional flow structure of the inlet at $\mathrm{Ma}_{\infty}=0.24$ is contoured by the total pressure recovery in axial slices in Figure 5. The total pressure recovery in the T-duct can be split into two parts, i.e., the left part which is filled by flow with low energies and the right part that is filled by flow with high energies. Here, the flow with low energies is generated near the splitting point due to suction effect of the turbine engine during operation which causes slight reverse flow from the E-duct and S-duct. With increasing axial position, the flow region of low energies enlarges. But the minimum total pressure recovery increases from 0.86 to 0.90 due to flow mixing within the T-duct. Contrarily, the flow region with high energies suppresses, whereas the maximum total pressure recovery remains on an equivalent value of 0.99 . Regarding the E-duct and the S-duct, the total pressure recovery stays above 0.96 without significant alterations at different axial positions.

In order to further examine the aerodynamic performance of the T-duct quantitatively, the influences of different angles of attack are considered. Figures 6(a) and 6(b) compare the total pressure recovery at the exit plane of the $\mathrm{T}$ duct with 0 and 8 degrees of angles of attack at $\mathrm{Ma}_{\infty}=0.24$ . In general, they exhibit similar total pressure recovery distributions. The averaged total pressure recovery at 8 degrees of angle of attack is only $0.4 \%$ smaller than that at 0 degree of angle of attack. Moreover, the effects of the angle of attack on Mach number distributions at the exit plane of the $\mathrm{T}$ - duct are also nearly negligible, as shown in Figures 6(c) and $6(\mathrm{~d})$. The averaged exit Mach number at 8 degrees of the angle of attack is about $3.8 \%$ higher than that at 0 degree of angle of attack.

In general, rather weak influence of the angle of attack on aerodynamic performance of the T-duct is detected, suggesting that the performance of the turbine engine will seldom be affected by the variation of angle of attack during takeoff/landing of flight vehicles. The detailed physical quantities representing the aerodynamic performance of the T-duct under different low speed inflow conditions are summarized in Table 1, where $\alpha$ denotes the attack angle, $\sigma$ denotes the total pressure recovery, and $\mathrm{Ma}_{\text {out }}$ is the exit Mach number.

3.2. Experimental Results. The axial pressure distributions on surfaces of the two T-ducts under different rotational speeds of the turbine engine are provided in Figure 7, where panels (a)-(d) correspond to the axial pressure distributions of the right T-duct in the $x y$ plane, the right T-duct in the $x z$ plane, the left T-duct in the $y z$ plane, and the left T-duct in the $x z$ plane, respectively. Overall, the pressure along the surface shows almost monotonical increment with $X$ at small rotational speeds (i.e., 35000 and $71000 \mathrm{rpm}$ ). For rotational speeds above $71000 \mathrm{rpm}$, the pressure distributions exhibit a down-up trend where the minimum pressure is located near $X=0.5 \mathrm{~m}$, corresponding to the splitting point. With increasing rotational speed of the turbine engine, the back pressure for the inlet within the current inflow speed range decreases, leading to a decrement of the surface pressure accordingly. As shown in Figure 7, the axial pressure distributions show similar tendencies at high rotational speeds but lack of complete symmetry for the two T-ducts which can be attributed to two reasons. Firstly, the two turbine engines are controlled individually without synchronization during wind tunnel experiments, resulting in weak asymmetrical aerodynamic performance of each turbine engine which further affects the pressure distributions of the inlet. Secondly, mechanical oscillations of the inlet model caused by the working turbine engine during the test may also contribute to the difference of the pressure distributions.

Figure 8 further compares the pressure distributions along the surface of the right T-duct in the $x z$ plane at different inflow Mach numbers, where panel (a) denotes the ground test at inflow speed $\mathrm{Ma}_{\infty}=0$, panels (b) $-(\mathrm{d})$ denote the wind tunnel test at inflow speeds $\mathrm{Ma}_{\infty}=0.06,0.15$, and 0.24 , respectively. The surface pressures of the right T-duct in the $x z$ plane exhibit similar curve shapes for different inflow speeds, i.e., the lowest pressure is located near $X=$ $0.5 \mathrm{~m}$ and decreases with rotational speed. But with increasing $\mathrm{Ma}_{\infty}$, the lowest pressure increases accordingly, e.g., from $72 \mathrm{kPa}$ at $\mathrm{Ma}_{\infty}=0$ to $88 \mathrm{kPa}$ at $\mathrm{Ma}_{\infty}=0.24$, which is mainly attributed to the high total pressure loss within the T-duct at the ground state, as also revealed in Table 1. From $X=0.5 \mathrm{~m}$ to the exit plane, the surface pressure increases which is related to the variation of the cross-sections from rectangular to circular with a weak expansion ratio of 1.25 of the T-duct.

Besides the influence of inflow speed, the angle of attack also represents as a critical parameter in determining the 


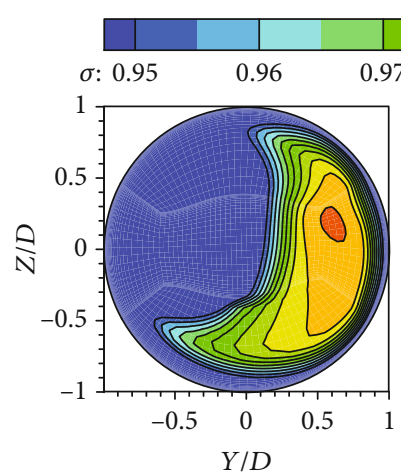

(a)

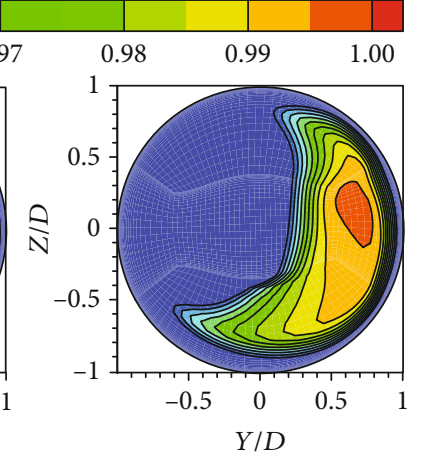

(b)

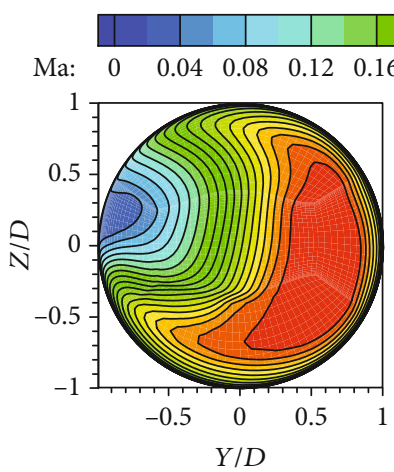

(c)

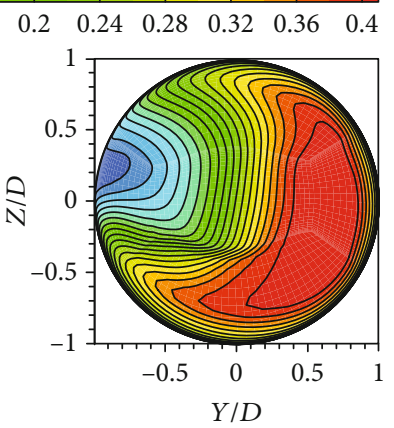

(d)

Figure 6: Total pressure distributions on the exit plane of the right T-duct at $\mathrm{Ma}_{\infty}=0.24$ with (a) 0 degree of angle of attack and (b) 8 degree of angle of attack. Mach number distributions on the exit plane of the right T-duct with (c) 0 degree of angle of attack and (d) 8 degrees of angle of attack.

TABle 1: Aerodynamic performance of the right T-duct under different inflow conditions.

\begin{tabular}{lcccccccccc}
\hline $\mathrm{Ma}_{\infty}$ & 0 & 0.06 & 0.06 & 0.06 & 0.15 & 0.15 & 0.15 & 0.24 & 0.24 & 0.24 \\
$\alpha\left(^{\circ}\right)$ & 0 & 0 & 4 & 8 & 0 & 4 & 8 & 0 & 4 & 8 \\
$\sigma$ & 0.880 & 0.897 & 0.897 & 0.906 & 0.910 & 0.916 & 0.916 & 0.959 & 0.955 & 0.955 \\
$\mathrm{Ma}_{\text {out }}$ & 0.403 & 0.400 & 0.401 & 0.378 & 0.412 & 0.394 & 0.394 & 0.314 & 0.326 & 0.326 \\
\hline
\end{tabular}

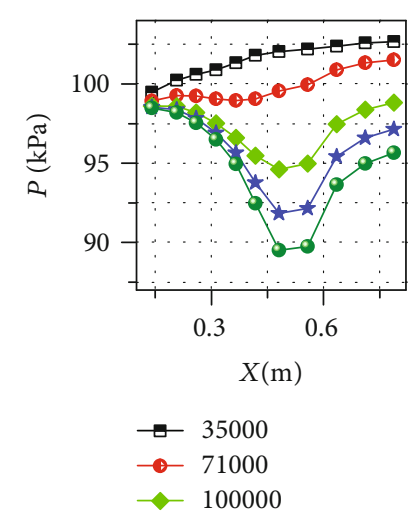

(a)

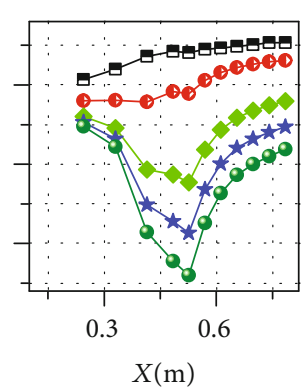

$X(\mathrm{~m})$

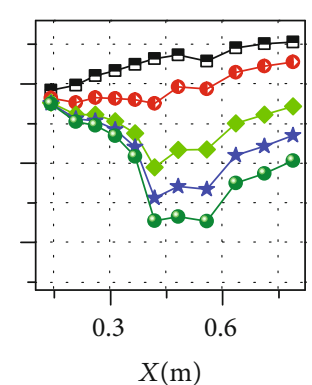

$X(\mathrm{~m})$

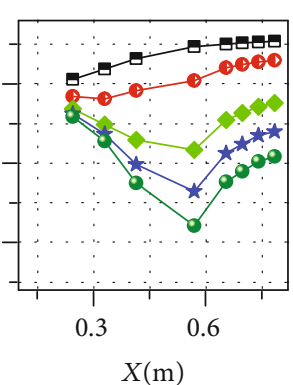

$\star$
$\rightarrow-110000$
$\rightarrow 17000(\mathrm{rpm})$

(c)

(d)

Figure 7: Axial pressure distributions on surfaces of the two T-ducts under different rotational speeds of the turbine engine at $\mathrm{Ma}_{\infty}=0.24$. Panels (a)-(d) correspond to the axial pressure distributions of (a) the right T-duct in the $x y$ plane, (b) the right T-duct in the $x z$ plane, (c) the left T-duct in the $x y$ plane, and (d) the left T-duct in the $x z$ plane, respectively.

gas turbine engine performance at low speeds especially during takeoff/landing of flight vehicles. The performance of the T-duct at different angles of attack with a fixed yaw angel of 4 degrees is shown in Figure 9 at $\mathrm{Ma}_{\infty}=0.15$, where panels (a)-(c) correspond, respectively, to the pressure distributions along the surface of the right T-duct at angles of attack of 0,4 , and 8 degrees. The surface pressure clearly decreases with increasing rotational speed of the turbine engine. The surface pressure distributions show similar tendencies in the $x z$ plane under various rotational speeds, i.e., a nearly constant surface pressure at low speed and an up-down distribution lineshape at high speed with the minimum pressure located near the splitting point. Interestingly, the variations of the pressure distributions versus angles of attack between 0 and 8 degrees are extremely weak regarding both tendency of the curves and magnitude of the pressure (e.g., less than $3 \%$ deviation of the magnitude), indicating that the aerodynamic performance of the turbine engine is seldom affected by the angle of attack which is consistent with the previous numerical results.

The contours of the total pressure recovery at the exit plane of the right $\mathrm{T}$-duct at $\mathrm{Ma}_{\infty}=0.24$ with different angles 


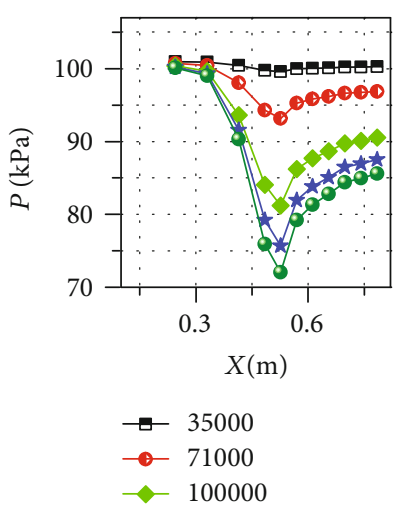

(a)

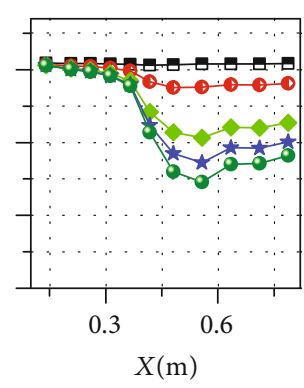

(b)

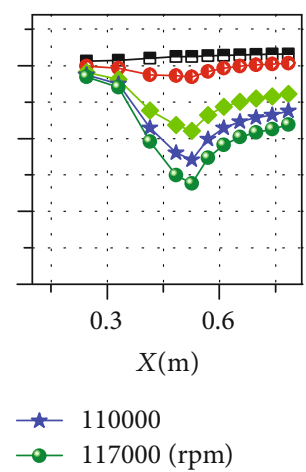

(c)

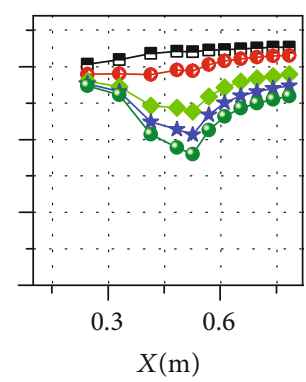

(d)

Figure 8: Effect of inflow speeds on the pressure distributions along the surface of the right T-duct in the $x z$ plane under different rotational speeds of the turbine engine. (a) Ground test at inflow speed $\mathrm{Ma}_{\infty}=0$; (b-d) wind tunnel test at inflow speeds of $\mathrm{Ma}_{\infty}=0.06,0.15$, and 0.24 , respectively.

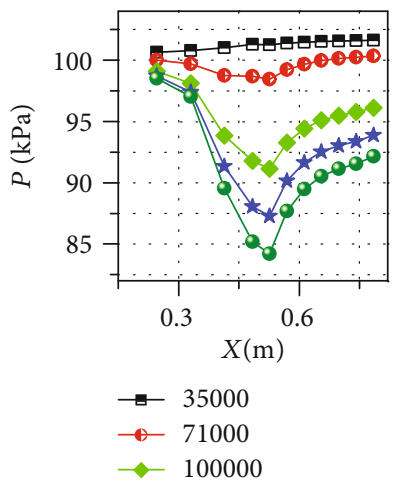

(a)

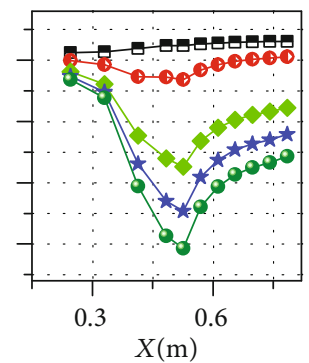

$\star 110000$

$\multimap 117000(\mathrm{rpm})$

(b)

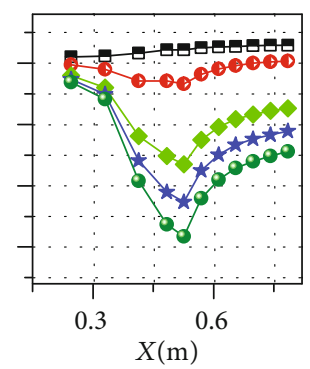

(c)

FIGURE 9: Pressure distributions along the surface of the right T-duct in the $x z$ plane under different rotational speeds of the turbine engine at fixed $\mathrm{Ma}_{\infty}=0.15$ and yaw angle of 4 degrees with (a) 0 degree of angle of attack, (b) 4 degrees of angle of attack, and (c) 8 degrees of angle of attack.

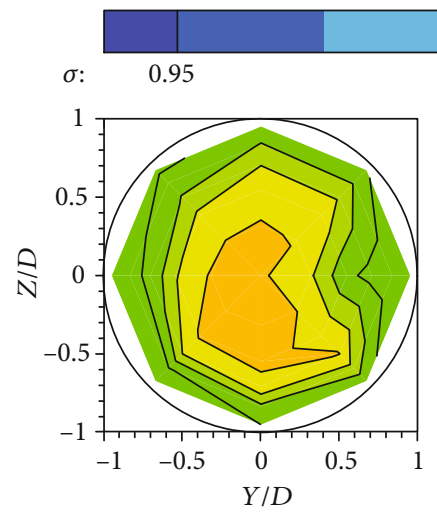

(a)

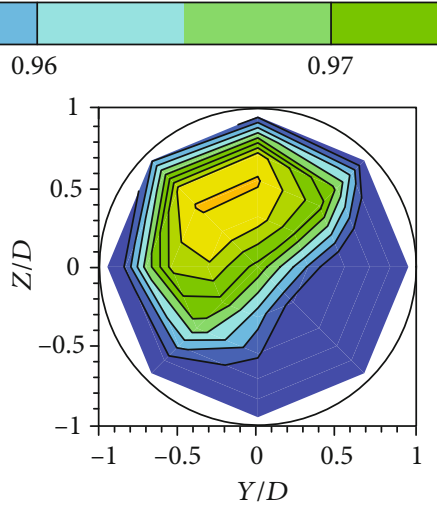

(b)

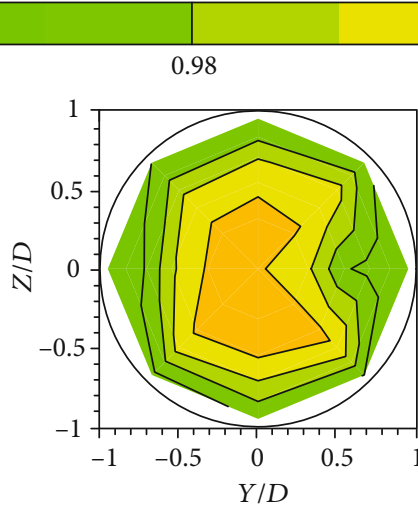

(c)

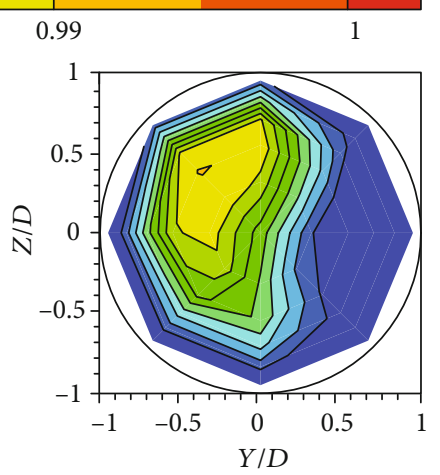

(d)

Figure 10: Total pressure distributions on the exit plane of the right T-duct at $\mathrm{Ma}_{\infty}=0.24$ with (a) 0 degree of angle of attack and $70000 \mathrm{rpm}$, (b) 0 degree of angle of attack and $117000 \mathrm{rpm}$, (c) 8 degrees of angle of attack and $70000 \mathrm{rpm}$, and (d) 8 degrees of angle of attack and $117000 \mathrm{rpm}$. 
of attack and rotational speeds are sketched in Figure 10. With increasing rotational speeds of the turbine engine, the total pressure recovery decreases significantly due to reverse flow near the splitting point which results in large energy loss. Meanwhile, the location of the region with high total pressure recovery shifts from the left-bottom side at $70000 \mathrm{rpm}$ to the left-upper side at $117000 \mathrm{rpm}$ regardless of the angle of attack, indicating that the reverse flow inside the inlet only attributes to total pressure loss at high rotational speeds of the turbine engine. In comparison with the total pressure recovery contours in panels (b) and (d) at the fixed rotational speed $117000 \mathrm{rpm}$ but with different angles of attack, the region with high total pressure recovery in the T-duct suppresses slightly with increasing angle of attack. However, the effect of the angle of attack on the aerodynamic performance is much weaker compared to the influence of rotational speed, as aforementioned. For instance, the averaged total pressure recovery at the exit plane is 0.957 for 0 degree of angle of attack which is equivalent to 0.959 for 8 degrees of angle of attack at $117000 \mathrm{rpm}$. This value however is $2 \%$ lower than 0.978 for 8 degrees of angle of attack at $70000 \mathrm{rpm}$. The comparison of the total pressure distributions between simulation (Figure 6) and experimental results also exhibits good consistency and confirms that flow with high energies is located on the right side while flow with low energies remains on the left side of the right T-duct.

Another important parameter, i.e., the flow distortion $\mathrm{DC}_{90}$ at the exit plane of the T-duct which is defined as ( $\left.p_{\text {mean }}-p_{90}\right) / q_{f}$, can also be quantitatively computed from the total pressure recovery contour. For example, $\mathrm{DC}_{90}$ at inflow speed $\mathrm{Ma}_{\infty}=0.15$ with 0 degree of angle of attack can be computed as $0.32,0.2,0.3$, and 0.28 at 35000, 71000, 100000 , and $117000 \mathrm{rpm}$, respectively, which are all within the distortion margin of classical gas turbine engines [18]. Additionally, the mass flow ratio of the right $\mathrm{T}$-duct (defined as the ratio of the mass at the exit plane of the T-duct to the total captured mass) at 0 degree of angle of attack can be calculated as $0.67,0.46,0.36$, and 0.3 at inflow speeds of $\mathrm{Ma}_{\infty}$ $=0,0.06,0.15$, and 0.24 , respectively. Note that the mass flow ratio of the right $\mathrm{T}$-duct at $\mathrm{Ma}_{\infty}=0$ is above 0.5 due to reverse flow from both the E-duct and the S-duct, which will be addressed in the following section. In general, the mass flow ratio decreases with increasing inflow speed in the investigated low speed range.

3.3. Comparison and Discussion. To provide a further detailed quantitative comparison between numerical and experimental results, the pressure distributions along the $\mathrm{T}$ duct and the averaged total pressure recovery at the exit plane of the T-duct are compared in Figure 11. The simulation is conducted by applying a proper backpressure to get the equivalent mass flow rate of the T-duct as in the experiment at $117000 \mathrm{rpm}$. The simulated curve shows a similar axial pressure distribution with the experimental data collected at $117000 \mathrm{rpm}$ and suggests the same location of the minimum pressure, as shown in Figure 11(a). The biggest pressure deviation is less than $2 \%$, guaranteeing the accuracy of the simulated physical quantities given in Table 1. Figure 11(b) further compares the averaged total pressure recovery $\sigma$ versus the Mach function $q(\mathrm{Ma})$ at the exit plane of the T-duct between simulation and experiment. It can be found that the total pressure recovery decreases with increasing $q(\mathrm{Ma})$ due to higher mass flow rate and accordingly stronger reverse flow inside the inlet, corresponding to the process of increasing rotational speed of the turbine engine in the experiment or increasing backpressure of the T-duct in the simulation. With increasing inflow speed, the averaged total pressure increases as well, and the difference between simulation and experiment is reduced. For instance, the averaged deviation of the total pressure recovery between simulation and experiment is $2 \%$ at $\mathrm{Ma}_{\infty}=0$, which decreases to only $0.5 \%$ at $\mathrm{M}$ $\mathrm{a}_{\infty}=0.24$.

Within the investigated low speed range, one of the most distinct differences between the multiduct inlet and the traditional inlet lies in the flow distortion among different ducts. Figure 12 provides a slice comparison $(Z / D=0.5)$ of flow structures in the T-duct between $\mathrm{Ma}_{\infty}=0$ and 0.24 . At $\mathrm{M}$ $\mathrm{a}_{\infty}=0$, severe reverse flow can be observed from S-duct to $\mathrm{T}$-duct as the turbine engine requires a large amount of incoming air mass which is however insufficient only from the intake of the inlet at this ground state. This reverse flow also results in a significant total pressure loss within the $\mathrm{T}$ duct, i.e., $\sigma=0.88$. When the inflow speed increases to $M$ $\mathrm{a}_{\infty}=0.24$, the incoming air mass is readily sufficient for the downstream turbine engine. The reverse flow phenomenon thus vanishes, where a high total pressure recovery of 0.96 is achieved within the T-duct.

\section{Conclusions}

In the present paper, the inward-turning multiduct inlet for turbine-based combined cycle engines is investigated numerically and experimentally at low speeds with $\mathrm{Ma}_{\infty}<0.24$. The aerodynamic performance of the T-duct, represented by the total pressure recovery and the axial pressure distributions versus different angles of attack, inflow Mach numbers, and rotational speeds, is emphasized in our work. The total pressure recovery of the T-duct is weakly affected by the angle of attack within the investigated low speed range, which is of crucial importance for takeoff/landing of flight vehicles. With decreasing rotational speed of the turbine engine and increasing inflow Mach number, the total pressure recovery and the surface pressure of the T-duct decreases. The maximum deviation between the simulation and experimental results is only $3 \%$ in terms of both total pressure recovery and surface pressure distributions. The two symmetrical T-ducts however exhibit weak asymmetrical aerodynamic performance during experiments due to nonsynchronization as well as mechanical oscillation of the two turbine engines. The minimum surface pressure is located near the splitting section, which suggests the position of the highest energy loss inside the T-duct and provides the guidance for future optimization of the duct. The averaged total pressure recovery of the T-duct at $\mathrm{Ma}_{\infty}$ $=0.24$ is about 0.96 , which is acceptable for the turbine engine to generate sufficient thrust for horizontal takeoff. At $\mathrm{Ma}_{\infty}=0$, an intriguing reverse flow from the S-duct to the $\mathrm{T}$-duct weakens the total pressure recovery inside the T-duct, 


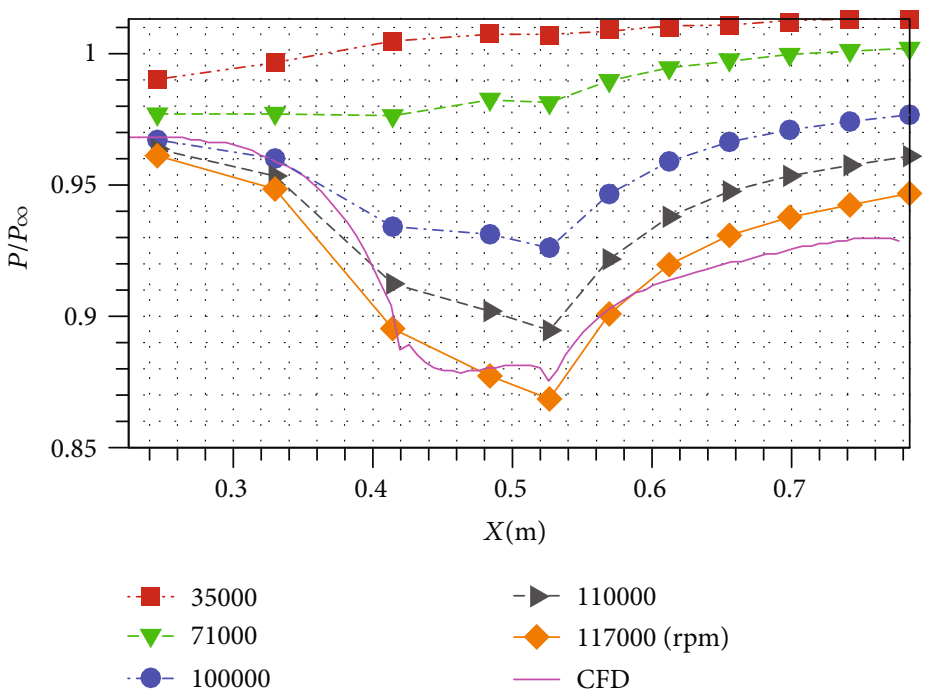

(a)

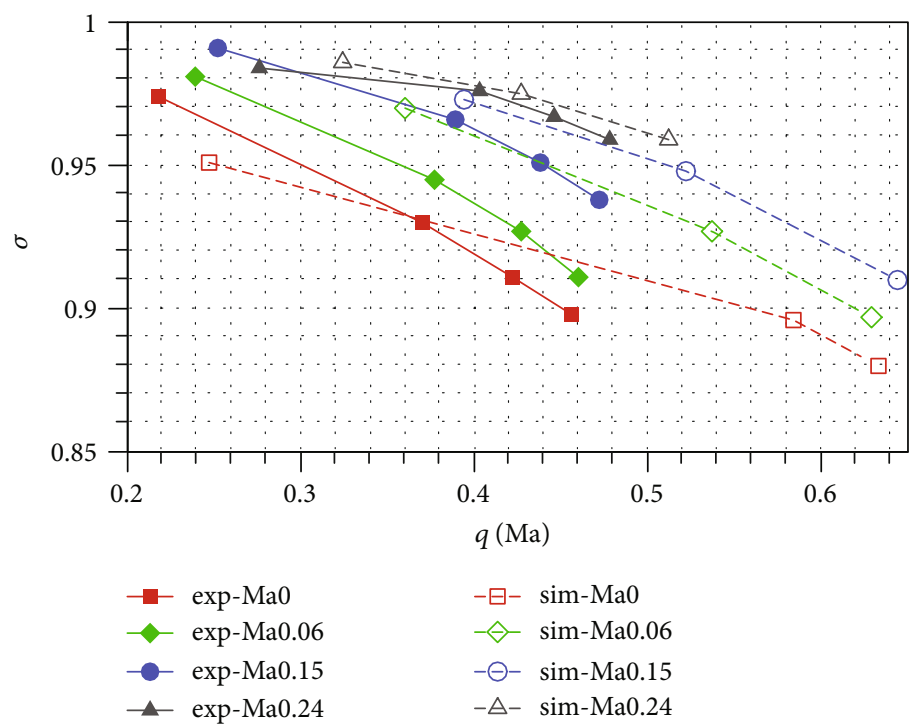

(b)

FIGURE 11: Comparison between simulation and experiment: (a) pressure distributions along the T-duct; (b) averaged total pressure recovery versus $q(\mathrm{Ma})$ at the exit plane of the T-duct.
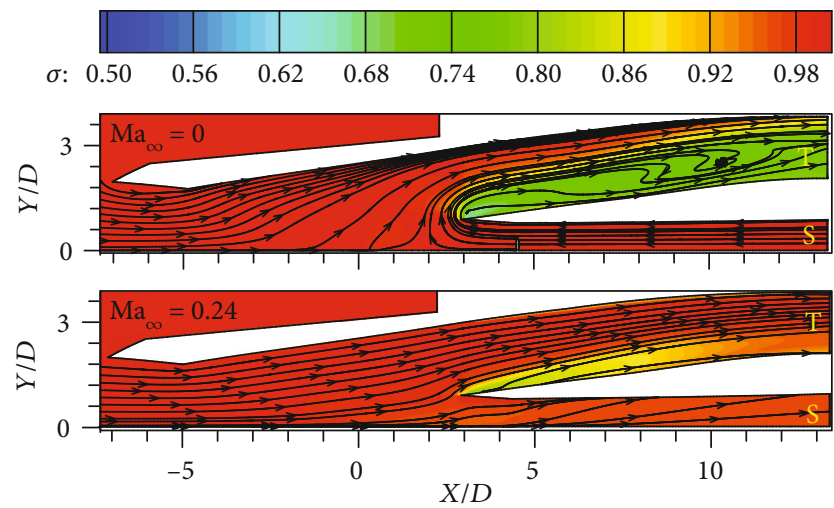

Figure 12: Comparison of the flow structures in the T-duct at $\mathrm{Ma}_{\infty}=0$ and 0.24 . which is also attributed as the most distinct flow feature in the multiduct inlet within the low speed range.

\section{Data Availability}

The data generated or analyzed during this study are available from the corresponding authors on reasonable request.

\section{Conflicts of Interest}

The authors declare that they have no conflicts of interest.

\section{Acknowledgments}

This study is cosupported by the National Natural Science Foundation of China (No. 51606161), the Fundamental 
Research Funds for the Central Universities (No. 20720170055), and the Aeronautical Science Foundation of China (No. 2018ZB68008). The authors also thank the Jiangsu Province Key Laboratory of Aerospace Power System and the China Academy of Aerospace Aerodynamics for the financial support of this work.

\section{References}

[1] J. Steelant, "Sustained hypersonic flight in Europe: technology drivers for LAPCAT II," in 16th AIAA/DLR/DGLR International Space Planes and Hypersonic Systems and Technologies Conference, Bremen, Germany, October 2009.

[2] J. Steelant, R. Varvill, S. Defoort, K. Hannemann, and M. Marini, "Achievements obtained for sustained hypersonic flight within the LAPCAT-II project," in 20th AIAA International Space Planes and Hypersonic Systems and Technologies Conference, Glasgow, Scotland, July 2015.

[3] H. Kobayashi and H. Taguchi, "Performance analysis of Mach 5 hypersonic turbojet developed in JAXA," in 18th AIAA/3AF International Space Planes and Hypersonic Systems and Technologies Conference, Tours, France, September 2012.

[4] M. J. Bulman and A. Siebenhaar, "Combined cycle propulsion: Aerojet innovations for practical hypersonic vehicles," in 17th AIAA International Space Planes and Hypersonic Systems and Technologies Conference, San Francisco, California, April 2011.

[5] A. Siebenhaar and T. J. Bogar, "Integration and vehicle performance assessment of the Aerojet "Trijet" combined-cycle engine," in 16th AIAA/DLR/DGLR International Space Planes and Hypersonic Systems and Technologies Conference, Bremen, Germany, October 2009.

[6] B. Wei, W. Ling, F. Luo, and Q. Gang, "Propulsion performance research and status of TRRE engine experiment," in 21st AIAA International Space Planes and Hypersonics Technologies Conference, Xiamen, China, March 2017.

[7] H. Yang, J. Ma, Y. Man, S. Zhu, W. Ling, and X. Cao, "Numerical simulation of variable-geometry inlet for TRRE combined cycle engine," in 21st AIAA International Space Planes and Hypersonics Technologies Conference, Xiamen, China, March 2017.

[8] C. Zhu, G. Huang, Y. You, and M. Zhou, "Performance comparison between internal waverider inlet and typical sidewall compression inlet," Journal of Propulsion Technology, vol. 32, no. 2, pp. 151-158, 2011.

[9] S. Kubota, K. Tani, and G. Masuya, "Aerodynamic performances of a combined cycle inlet," Journal of Propulsion and Power, vol. 22, no. 4, pp. 900-904, 2006.

[10] T. Brien, D. Davis, and J. Colville, "The advanced combinedcycle integrated inlet test program - test results," in 15th AIAA International Space Planes and Hypersonic Systems and Technologies Conference, Dayton, Ohio, April 2008.

[11] Q. Qin, J. Xu, and S. Guo, "Aeroelastic study of the splitter plate in turbine-based combined-cycle inlet," Journal of Aircraft, vol. 55, no. 5, pp. 1914-1928, 2018.

[12] C. Zhu, X. Zhang, F. Kong, and Y. You, "Design of a ThreeDimensional Hypersonic Inward-Turning Inlet with TriDucts for Combined Cycle Engines," International Journal of Aerospace Engineering, vol. 2018, Article ID 7459141, 10 pages, 2018.
[13] Y. You and D. Liang, "Investigation of internal compression flowfield for internal waverider-derived inlet," Acta Aerodynamica Sinica, vol. 26, no. 2, pp. 203-207, 2008.

[14] J. Guo, G. Huang, Y. You, and D. Liang, "Study of internal compression flow field for improving the outflow uniformity of internal waverider inlet," Journal of Astronautics, vol. 30, no. 5, pp. 1934-1940, 2009.

[15] M. Zhou, G. Huang, C. Zhu, and Y. You, "Research on start ability of modular internal waverider inlet," Acta Aeronautica et Astronautica Sinica, vol. 33, no. 5, pp. 818-827, 2012.

[16] J. Davic and A. Midea, "Propulsion and aerodynamic analysis of the beta II two-stage-to-orbit vehicle," in Guidance, Navigation and Control Conference, Hilton Head, SC, USA, August 1992.

[17] H. Zhang, X. Liu, R. Guo, and L. Xie, "Design of turbo diffuser for TBCC inlet based on characteristics of turbo mode," Journal of Aerospace Power, vol. 29, no. 1, pp. 181-191, 2014.

[18] F. Guo, F. Gui, Y. You, J. Zhu, and C. Zhu, "Experimental study of TBCC engine performance in low speed wind tunnel," Journal of propulsion and Technology, 2019. 


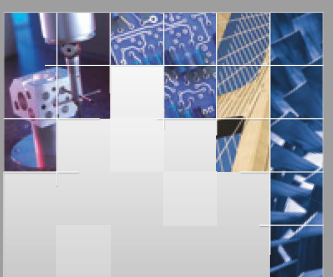

\section{Enfincering}
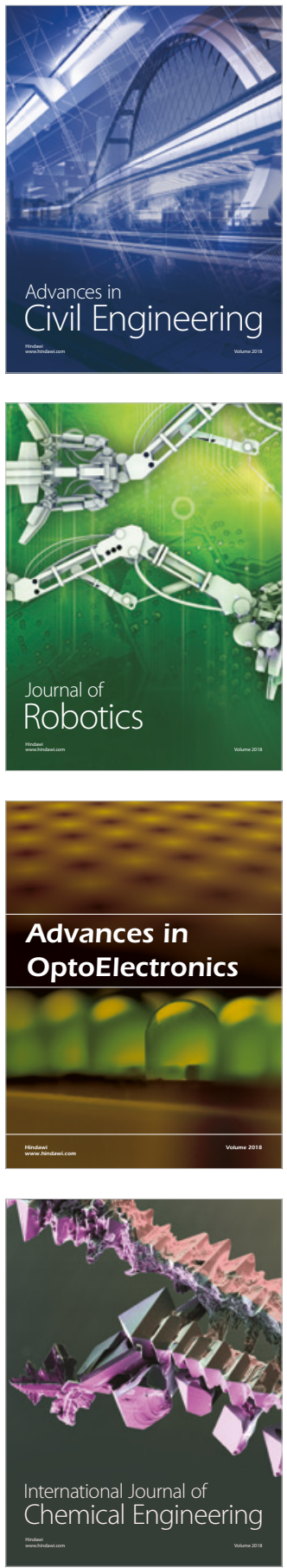

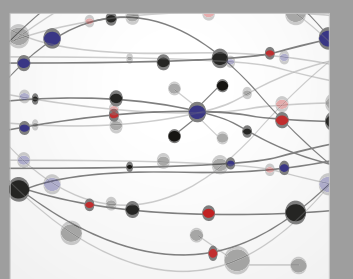

\section{Rotating \\ Machinery}

The Scientific World Journal

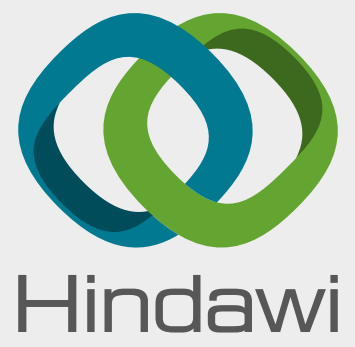

Submit your manuscripts at

www.hindawi.com
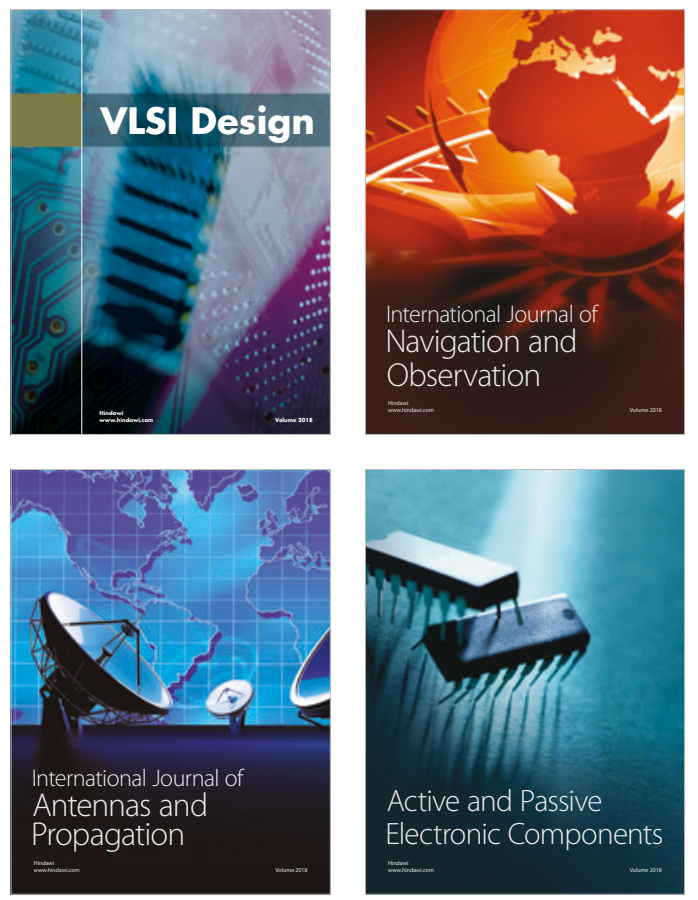
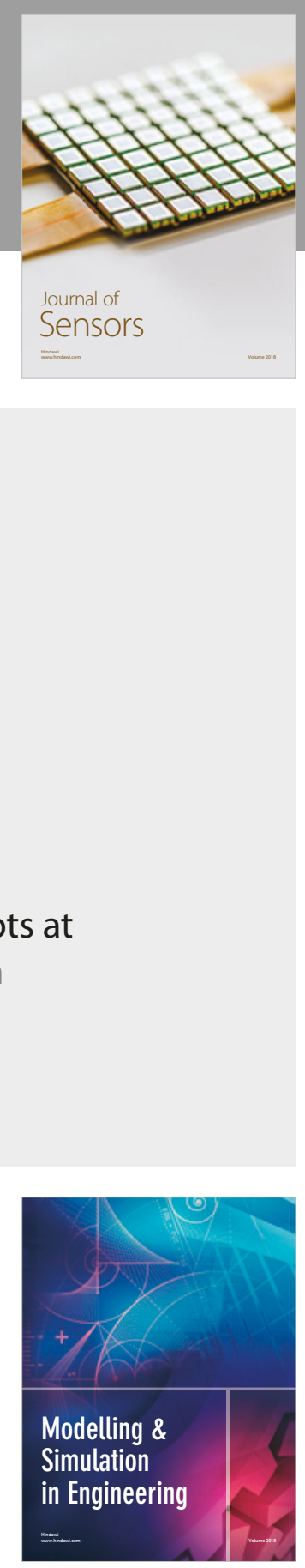

\section{Advances \\ Multimedia}
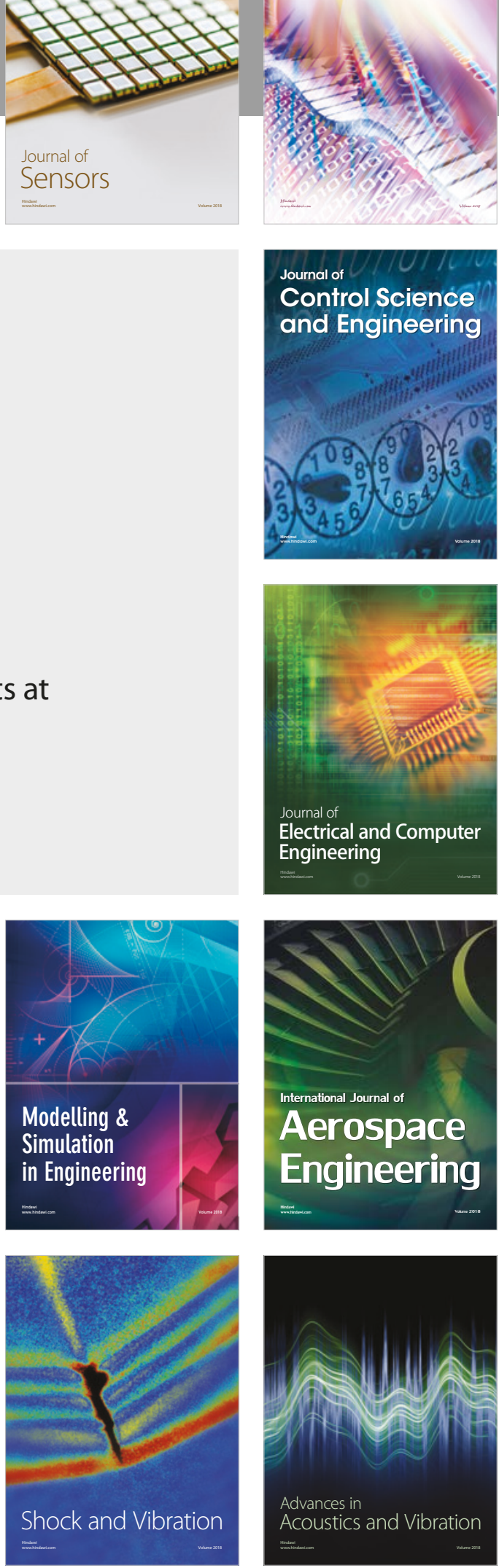